\title{
Removal of typical pharmaceutically active compounds in sewage sludge using mesophilic and thermophilic anaerobic digestion processes
}

\author{
Haidong Zhou • Jiaoyan Zhou $\cdot$ Meng Wang • \\ Xuelian Wang • Qianqian Zhang • Qingjun Zhang • \\ Yong Zhan
}

Received: 30 October 2013/Revised: 17 March 2014/ Accepted: 12 May 2014/Published online: 25 June 2014

(C) Islamic Azad University (IAU) 2014

\begin{abstract}
The removal of four pharmaceutically active compounds, i.e., anti-inflammatory painkiller diclofenac (DCF), lipid-regulating agent clofibric acid (CFA), epilepsy drugs carbamazepine (CBM), and broad-spectrum anti-bacterial agent triclosan (TCS), present in sewage sludge was investigated using anaerobic digestion processes in the mesophilic and thermophilic modes. Sludge retention times (SRTs) were set at 10, 15, and 20 days, respectively, for the mesophilic mode and 7, 15, and 20 days, respectively, for the thermophilic mode. The effective isolation and purification pre-treatment to extract the target compounds from the sewage sludge samples were firstly established, followed by gas chromatographymass spectrometer analysis to identify and quantify them. The removal efficiencies of the target compounds could be raised to a certain extent with the increase on SRTs, especially under the mesophilic condition. The removal of CFA and TCS under thermophilic condition hardly varied when the SRTs were above 15 days. All the compounds could be partly removed from the sewage sludge under the two temperature conditions, particularly TCS that was reduced by about $74 \%$. Besides, CFA, firstly reported in this study, could be reduced by maximal $65 \%$. On the whole, the thermophilic mode was more conducive to the removal of CBM and TCS, but did not have a noticeable effect on the removal of CFA. Furthermore, DCF could be better removed in the mesophilic mode. In addition,
\end{abstract}

\footnotetext{
H. Zhou (凶) · J. Zhou $\cdot$ M. Wang $\cdot$ X. Wang ·

Qianqian Zhang · Qingjun Zhang · Y. Zhan

School of Environment and Architecture, University of Shanghai for Science and Technology, No. 516, Jungong Road, Shanghai 200093, China

e-mail: zhouhaidong@usst.edu.cn
}

$\mathrm{NH}_{3}-\mathrm{N}$ accumulation in this measured range might positively affect the removal of the selected compounds, particularly in the mesophilic mode.

Keywords Removal efficiency - Sludge retention time Mesophilic anaerobic digestion - Ammonia nitrogen

\section{Introduction}

Pharmaceutically active compounds (PhACs) represent an overgrowing portion of organic micro-pollutants of the environment and are increasingly concerned. They usually reach sewage treatment plants (STPs) in metabolized and/ or unmetabolized forms after human consumption. STPs are frequently considered as the main points of discharge of PhACs into the environment, and therefore, PhACs in the effluent sewage have been extensively investigated and detected (Aguayo et al. 2010; Jelic et al. 2011; Yang et al. 2011; Zhou et al. 2010). In addition, PhACs can be absorbed onto bacterial lipid structure and fat fraction of the sludge through hydrophobic interactions (e.g., aliphatic and aromatic groups) (Radjenovic et al. 2009); therefore, the concerns and researches on their concentrations, behavior, and fate in sewage sludge are growing. Khan and Ongerth (2002) reported on the concentrations of six PhACs in both fresh primary and secondary sludges, and carbamazepine (CBM) was present at the highest concentration, up to $0.01 \mu \mathrm{g} / \mathrm{L}$ (dry weight). In the previous investigation conducted by Radjenovic et al. (2009), sludge samples including the primary sewage sludge and activated sludge were analyzed, and pharmaceuticals, i.e., ibuprofen, ketoprofen, diclofenac (DCF), ofloxacin, and azithromycin, were detected at concentrations up to $741.1,336.3,380.7$, 454.7 , and $299.6 \mathrm{ng} / \mathrm{g}$ dry weight, respectively. 
Due to their adsorption onto often negatively charged polysaccharide structures on the outside of bacterial cells through electrostatic interactions (e.g., amino groups), and/ or chemical binding to bacterial proteins and nucleic acids, low or pseudo-low biodegradation rate, bioconcentration, and bioaccumulation in aquatic organisms, inevitably PhACs would pose unpredicted effects on the organisms which are exposed to them for long term (Lee et al. 2011). Bioassays of the ecotoxicology of CBM, clofibric acid (CFA), and DCF performed on bacteria, algae, microcrustaceans, and fishes (Ferrari et al. 2003) verified that CBM seemed to be the most hazardous compound. Saravanan et al. (2011) also tested the toxic effects DCF and CFA at different concentrations in a common carp Cyprinus carpio for a period of $96 \mathrm{~h}$ with static bioassay method. At all concentrations, red blood cell, $\mathrm{Na}^{+}, \mathrm{K}^{+}$, and glutamate oxaloacetate transaminase levels were decreased in the fishes treated with CFA and DCF. Consequences of long-term exposure to DCF up to 3 months were also evaluated using freshwater crustaceans (Daphnia magna and Moina macrocopa) and a fish (Oryzias latipes) by Lee et al. (2011). The presence of DCF at the concentration of $1 \mu \mathrm{g} / \mathrm{L}$ was reported to damage the liver and kidney cell functions in fish (Triebskorn et al. 2004). Besides, Nassef et al. (2010) also investigated the toxicity of three kinds of pharmaceuticals, CBM, DCF, and triclosan (TCS), through examining their effects on feeding behavior and swimming speed of adult Japanese medaka fish (O. latipes). Therefore, the environmental risks caused by $\mathrm{PhACs}$, especially in land use and utilization of sewage sludge, should be given enough attention.

With the extensions of sewage treatment volume and the increasingly stringent requirements of treatment, the production of sludge is quite enormous; thus, the treatment and disposal of sewage sludge are becoming more and more emergent (Hospido et al. 2010). Sewage sludge can be viewed as a resource for land use in agriculture, biomass, and value-added products. (Barnab et al. 2009; Garfí et al. 2011; Li et al. 2014). However, it is necessary to consider residual contaminants when sewage sludge is released into the environment, due to their direct environmental harms or potential risks to the safety of the environment (Heberer 2002). Therefore, it is of the great interest to investigate the fate and effective removal of $\mathrm{PhACs}$ in sewage sludge treatment and disposal related to the sludge land use and resource utilization.

Anaerobic digestion (AD) has been extensively used and proven to be the most efficient treatment technology to stabilize organic substrates in sewage sludge generated from STPs (Carballa et al. 2007; Mudhoo and Kumar
2013). The mesophilic AD is most widely adopted for the treatment of sewage sludge due to its relatively simple operation and control. In comparison with the mesophilic process, the thermophilic AD shows some advantages, such as an acceleration of the biochemical reactions, a greater extent of pathogen reduction, and an effective degradation of organic matter. The thermophilic treatment is also increasingly introduced because of the increased demands on sewage sludge treatment and reduction (Merrylin et al. 2013). Although in recent researches, Narumiya et al. (2013) and Samaras et al. (2013) reported the fate and removal of some pharmaceuticals during mesophilic and/or thermophilic ADs of sewage sludge in full-scale STPs; there is still very limited information about the variations and removal of PhACs during the processes.

In this study, the mesophilic and thermophilic ADs were adopted to remove the typical PhACs, i.e., anti-inflammatory painkiller DCF, lipid-regulating agent CFA, epilepsy drug CBM, and broad-spectrum anti-bacterial agent TCS, which are widely used for human health and frequently detected in the natural environment. Effective isolation and purification to extract the compounds from sewage sludge samples were also established before the analysis and quantification of analytes by GC-MS. Sludge retention times (SRTs) and operating temperature were considered as important factors to investigate the performances of ADs. Besides, the effects of $\mathrm{NH}_{3}-\mathrm{N}$ on the removal were also analyzed. All the research was conducted in the laboratories of the School of Environment and Architecture of the University of Shanghai for Science and Technology (China). These experiments were made within the period October 2011-April 2013.

\section{Materials and methods}

\section{Sewage sludge}

Sewage sludge used in this work was collected from a STP located in the eastern Shanghai, China. The STP, built in 1920 , is nowadays the only oldest plant stably running in Asia, employing the mesophilic $\mathrm{AD}$ with one common reactor for the digestion of mixtures of primary and secondary sludges. It serves the population of about 800,000 people and is currently capable of treating $28,000 \mathrm{~m}^{3} /$ day sewage. Eighty percent of the sewage is from domestic wastewater and the rest is from industry. The sludge used in this work was taken from sludge circulation lines of biological treatment units in the STP. The main characteristics of the sludge are shown in Table 1. 
Table 1 Main characteristics and selected PhACs of the sewage sludge used in this work

\begin{tabular}{|c|c|c|c|c|c|c|c|c|c|c|c|c|}
\hline Indicator & $\mathrm{pH}$ & $\begin{array}{l}\text { COD } \\
(\mathrm{mg} / \mathrm{L})\end{array}$ & $\begin{array}{l}\mathrm{SS} \\
(\mathrm{mg} / \mathrm{L})\end{array}$ & $\begin{array}{l}\mathrm{VSS} \\
(\mathrm{mg} / \mathrm{L})\end{array}$ & $\begin{array}{l}\mathrm{NH}_{3}-\mathrm{N} \\
(\mathrm{mg} / \mathrm{L})\end{array}$ & $\begin{array}{l}\mathrm{TN} \\
(\mathrm{mg} / \mathrm{L})\end{array}$ & $\begin{array}{l}\mathrm{TP} \\
(\mathrm{mg} / \mathrm{L})\end{array}$ & $\begin{array}{l}\text { VFA } \\
(\mathrm{mg} / \mathrm{L})\end{array}$ & $\begin{array}{l}\text { CFA } \\
\text { (ng/L) }\end{array}$ & $\begin{array}{l}\mathrm{DCF} \\
(\mathrm{ng} / \mathrm{L})\end{array}$ & $\begin{array}{l}\mathrm{CBM} \\
(\mathrm{ng} / \mathrm{L})\end{array}$ & $\begin{array}{l}\mathrm{TCS} \\
\text { (ng/L) }\end{array}$ \\
\hline Value & 7.3 & 16,500 & 7,000 & 4,200 & 57 & 150 & 30 & 50 & 27.8 & 114.2 & 74.6 & 58.5 \\
\hline
\end{tabular}

Data are the means of measurements $(n>20)$

Chemicals and materials

The reference standards of CFA, DCF, CBM, and TCS were purchased from Shanghai ANPEL Scientific Instrument, China. All these standards were of high purity over $99 \%$. The standards were dissolved in methanol to prepare the stock solutions $(1 \mathrm{~g} / \mathrm{L})$ and working solutions. Standard stock solutions were stored at $-20{ }^{\circ} \mathrm{C}$ in the dark. All the solvents used were HPLC grade or higher. The derivatization reaction reagent, $N$, $O$-bis (trimethylsilyl) trifluoroacetamide (BSTFA) with $1 \%$ trimethylchlorosilane (TMCS), and methyl tert-butyl ether (MTBE) were purchased from Sigma-Aldrich, USA. Acetone, methanol, and dichloromethane were bought from Fisher, USA. Other reagents used in this study were of analytical grade or better. Ultrapure water was prepared with Aquapro Ultrapure Water System (China).

GF/B Glass fiber filters $(1 \mu \mathrm{m})$ were obtained from Whatman, USA. Cartridges (C8 opposition, $6 \mathrm{cc} / 200 \mathrm{mg}$ ) for solid-phase extraction (SPE) were supplied by Supelco, USA.

\section{Anaerobic digestion}

Two lab-scale stainless steel anaerobic digesters (the total volume of $25 \mathrm{~L}$ for each) were installed in parallel and continuously stirred to keep the homogenous mixture of sewage sludge. The external jackets of the digesters with auto-temperature controller were used to keep their inside temperature. One was operated in the mesophilic range $\left(37 \pm 2{ }^{\circ} \mathrm{C}\right)$, and the other in the thermophilic range $\left(55 \pm 2{ }^{\circ} \mathrm{C}\right)$. There were one inlet and two sampling mouths in the wall of each digester. One outlet for sludge discharge was set at the bottom of each digester. Sewage sludge collected from the sludge circulation lines of the STP was pumped into the each digester using peristaltic pump. Wet gas flow meter (LML-1, Beijing, China) was connected to each digester to count the gas production directly, together with $\mathrm{pH}$ meter (PHS-3C, Shanghai, China) monitoring acid-alkaline condition.
The start-up of a digester included two periods. During the first period (about 25 days), the inoculum sludge collected from the anaerobic digester of the STP was pumped into the digester, and the final filled volume was kept to $20 \mathrm{~L}$. At the first week, there was no sludge discharge or feeding. Then, the digester was operated on batch mode with the lower initial feeding load rate, i.e., $0.5 \mathrm{~L}$ sludge per day. Three operating factors were measured online: temperature, $\mathrm{pH}$, and biogas production. Apart from the online measurements, the operation was monitored in terms of solids, CODcr, volatile fatty acids (VFAs), $\mathrm{NH}_{3}-\mathrm{N}$, and TP twice or three times weekly. The period lasted till the variations of the factors were observed $<10 \%$ over the average values, and the digester was considered as basically stable (Coelho et al. 2011; Jang et al. 2014). During the second period, a continuous feeding at a relatively low organic load rate (OLR) with SRT kept at 20 days was applied for 1 month. Identically, all the above operating factors were monitored. The entire start-up period lasted about two and a half months. Some main indicators of the two digesters are present in Table 2 after the successful start-up.

Subsequently, the digesters were fed with the sludge previously spiked with the four selected compounds at certain levels. In order to obtain a homogenous spike in the entire volume of sludge, the spiked sludge was continuously stirred $2 \mathrm{~h}$ before its feeding. The SRTs, which could be regulated through the gradual adjustment of OLRs, were set at 10,15, and 20 days, respectively, for the mesophilic anaerobic digester and 7, 15, and 20 days, respectively, for the thermophilic one. The tests were launched after the two digesters ran for two or three SRT periods. Each test was done repeatedly. Samples of digested sludge were collected everyday during each test. Each sample was immediately pre-treated so as to accurately represent the variations of the target compounds during ADs.

\section{Analyses}

Sample pre-treatment and GC/MS measurements The sludge sample of $500 \mathrm{~mL}$ was pre-filtered with a $\mathrm{GF} / \mathrm{B}$ 
Table 2 Main indicators of the two anaerobic digesters after the successful start-up

\begin{tabular}{lllllllll}
\hline Anaerobic digester & $\begin{array}{l}\mathrm{CODcr} \\
(\mathrm{g} / \mathrm{L})\end{array}$ & $\begin{array}{l}\mathrm{SS} \\
(\mathrm{g} / \mathrm{L})\end{array}$ & $\begin{array}{l}\mathrm{VSS} \\
(\mathrm{g} / \mathrm{L})\end{array}$ & $\begin{array}{l}\mathrm{NH}_{3}-\mathrm{N} \\
(\mathrm{mg} / \mathrm{L})\end{array}$ & $\begin{array}{l}\mathrm{TP} \\
(\mathrm{mg} / \mathrm{L})\end{array}$ & $\begin{array}{l}\mathrm{VFA} \\
(\mathrm{mg} / \mathrm{L})\end{array}$ & $\begin{array}{l}\text { Gas production } \\
(\mathrm{L} / \mathrm{d})\end{array}$ & $\begin{array}{l}\text { Temperature } \\
\left({ }^{\circ} \mathrm{C}\right)\end{array}$ \\
\hline Mesophilic & $10.6-15.8$ & $12.4-17.4$ & $5.8-7.1$ & $5.5-9.2$ & $0.8-1.2$ & $248-425$ & 0.5 & $37-39$ \\
Thermophilic & $14.3-18.5$ & $14.6-17.2$ & $5.3-8.2$ & $6.2-9.0$ & $0.8-1.04$ & $270-480$ & 0.8 & $6.6-7.2$ \\
\hline
\end{tabular}

glass fiber filter by the vacuum pump. The filter was prewashed three times with acetone before use. The biosolid/ sludge fraction retained on the fiber was firstly dried in the temperature of $60-70{ }^{\circ} \mathrm{C}$ through drying oven. Afterward, the biosolid/sludge was ground in a mortar, mixed completely, and stored in amber bottles until analysis. The filtrate with $\mathrm{pH}$ value about 3 adjusted by $\mathrm{H}_{2} \mathrm{SO}_{4}$ addition was introduced to a $\mathrm{C} 8$ cartridge $(6 \mathrm{cc} / 200 \mathrm{mg})$ on a vacuum 12-position Extraction Manifold (Supelco, USA) by means of a PTFE tube for the solid-phase extraction (SPE) to extract the analytes. Before SPE, the cartridge was conditioned with $5 \mathrm{~mL}$ MTBE for three times and then rinsed by $5-\mathrm{mL}$ methanol for three times followed by $5-\mathrm{mL}$ ultrapure water for three times for equilibration. The extraction was done at a flow rate $<10 \mathrm{~mL} / \mathrm{min}$. The cartridge was eluted with $5 \mathrm{~mL}$ dichloromethane/acetone (7:3), and the extract was evaporated to dryness under a gentle nitrogen stream. Then, the dry residue was derivatized by adding $50 \mu \mathrm{L}$ pyridine and $100 \mu \mathrm{L}$ BSTFA (with $1 \%$ TMCS). The derivative was further dried, and the residue was redissolved in $100 \mu \mathrm{L} n$-hexane for GC/MS analysis. As for the analysis of biosolid/sludge fraction, an aliquot $(0.02 \mathrm{~g})$ of the stored sludge was extracted successively with $8 \mathrm{~mL}$ methanol/ $\mathrm{H}_{2} \mathrm{O}(5: 3)$ and then three times with $5 \mathrm{~mL}$ methanol. Each extraction was operated with sonication for $30 \mathrm{~min}$ at $50{ }^{\circ} \mathrm{C}$. The sludge slurry was centrifugated at $10,000 \mathrm{rmp}$ for $15 \mathrm{~min}$, and the supernatant was collected and combined. It was diluted to a final $500-\mathrm{mL}$ volume using ultrapure water for the SPE, which was the same procedure mentioned above.

GC/MS system, Agilent 7890/5975C-GC/MSD, USA, was used for the analysis of target compounds. The parameters for GC/MS described by Zhou et al. (2012) were adopted with minor modification. For the identification and qualitative analysis of the analytes, the full scan mode $(\mathrm{m} / \mathrm{z}=50-650)$ was firstly applied. The HP-5MS capillary chromatographic column was used to realize the separation of the compounds, and identification and verification of the compounds were achieved via the comparison of retention times and mass spectrum in samples with those of authentic standard compounds. Quantification was performed by comparing the integration of the selected ion chromatograms of each compound with that of the instrumental internal standard in the mode of selected ion monitoring (SIM). Calibration was made from 2 to $2,000 \mu \mathrm{g} / \mathrm{L}$ (10 points) using standard solution containing the four selected compounds. The recoveries of the target compounds in sewage sludge samples were determined using the spiked matrix with the standard compounds at $0.1,1.0$, and $5.0 \mu \mathrm{g} / \mathrm{L}$, respectively. All recovery studies were conducted in triplicate, with blank subtraction. The mean recoveries were $64.1-82.8 \%$ for CFA, $72.3-82.0 \%$ for DCF, $85.5-94.8 \%$ for CBM, and $68.7-90.6 \%$ for TCS. The calculated concentrations of analytes were corrected by the recoveries of the analytes in the samples. In addition, procedure blanks and solvent blanks were also treated and analyzed alongside with the measurements. The concentrations of the target compounds were calculated with both the aqueous part and the biosolid/sludge fraction of the sewage sludge samples.

Other chemical analyses Analyses of $\mathrm{COD}, \mathrm{TN}, \mathrm{NH}_{3}-\mathrm{N}$, TP, VFA, total solids (TS), and volatile solids (VS) were performed according to the standard methods (Clesceri et al. 2001; MOCC 2005). A 100-mL sewage sludge was taken from the digesters each time, immediately filtered through $0.45 \mu \mathrm{m}$ mixed cellulose ester filter. The filtrate was collected for the measurements of $\mathrm{COD}, \mathrm{TN}, \mathrm{NH}_{3}-\mathrm{N}$, TP, VFA, and the biosolid fraction was used to measure TS and VS.

\section{Results and discussion}

The selected PhACs, CFA, DCF, CBM, and TCS were detected in the feeding sewage sludge at the mean concentrations of $27.8,114.2,74.6$, and $58.5 \mathrm{ng} / \mathrm{L}$, respectively (Table 1). Reference standards were spiked to the sludge so as to ensure the detection of the compounds and represent their variations more effectively and clearly during ADs, and the initial concentrations of the compounds were set to $5 \mu \mathrm{g} / \mathrm{L}$, higher than their environmentally relevant concentrations.

The mesophilic AD was operated at SRTs 10, 15, and 20 days, respectively, and for the thermophilic reactor, 
Table 3 CODcr and $\mathrm{NH}_{3}-\mathrm{N}$ variations during the mesophilic and thermophilic ADs at different SRTs

\begin{tabular}{|c|c|c|c|c|c|c|}
\hline \multirow{2}{*}{$\begin{array}{l}\text { Anaerobic } \\
\text { digestion }\end{array}$} & \multirow{2}{*}{$\begin{array}{l}\text { SRT } \\
\text { (days) }\end{array}$} & \multicolumn{3}{|l|}{ CODcr } & \multicolumn{2}{|l|}{$\mathrm{NH}_{3}-\mathrm{N}$} \\
\hline & & $\begin{array}{l}\text { Untreated sludge } \\
(\mathrm{mg} / \mathrm{L})\end{array}$ & $\begin{array}{l}\text { Digested sludge } \\
(\mathrm{mg} / \mathrm{L})\end{array}$ & $\begin{array}{l}\text { Removal efficiency } \\
(\%)\end{array}$ & $\begin{array}{l}\text { Untreated sludge } \\
(\mathrm{mg} / \mathrm{L})\end{array}$ & $\begin{array}{l}\text { Digested sludge } \\
(\mathrm{mg} / \mathrm{L})\end{array}$ \\
\hline \multirow[t]{3}{*}{ Mesophilic } & 10 & 16,000 & 5,800 & 63.4 & 58 & 72 \\
\hline & 15 & 16,500 & 5,200 & 68.4 & 58 & 83 \\
\hline & 20 & 16,000 & 4,600 & 71.2 & 58 & 93 \\
\hline \multirow[t]{3}{*}{ Thermophilic } & 7 & 16,000 & 5,300 & 66.8 & 58 & 76 \\
\hline & 15 & 16,500 & 4,800 & 70.9 & 58 & 89 \\
\hline & 20 & 16,000 & 4,800 & 70.0 & 58 & 110 \\
\hline
\end{tabular}

SRTs were set to 7, 15, and 20 days, respectively. Regulation and control of SRTs of AD processes were achieved through the daily feeding load of the spiked sludge, considering the biosolid contents in both the feeding and the digesters. The variation and removal of the target PhACs under different operating conditions were examined. Each sewage sludge sample was pre-treated into an aqueous phase sample and a biosolid/sludge phase sample. Consequently, the detection and analysis for the target compounds were conducted on the two phase sub-samples, and their variation and removal in the two phases were investigated.

$\mathrm{COD}_{\mathrm{cr}}$ and $\mathrm{NH}_{3}-\mathrm{N}$ variations during anaerobic digestions at different SRTs

CODcr and $\mathrm{NH}_{3}-\mathrm{N}$ are the conventional indicators during AD of sewage sludge, representing the status and performances of ADs. Table 3 shows the variations of the two indicators during the mesophilic and thermophilic AD reactors at different SRTs. The two reactors did not demonstrate any inhibition from the spiked higher concentrations of PhACs and were on stable operation for the following tests. For the mesophilic condition, removal efficiencies of CODcr increased with SRTs and reached about $71 \%$ at SRT 20 days. In the case of the thermophilic condition, it seemed that removal efficiencies of CODcr could be optimally obtained at SRT 15 days, and the following extension on SRT would not benefit the removal. On the other hand, $\mathrm{NH}_{3}-\mathrm{N}$ concentrations went up with the increase of SRTs under the two temperature conditions, and more quickly under the thermophilic condition than the mesophilic condition. The increase on the $\mathrm{NH}_{3}-\mathrm{N}$ concentrations might be due to the degradation of
$\mathrm{N}$-containing organic substances and the release of ammonia nitrogen from the sludge during the AD processes.

PhACs removal during anaerobic digestions at different SRTs

Mesophilic anaerobic digestion When the sludge spiked with $5 \mu \mathrm{g} / \mathrm{L}$ of each selected pharmaceutical was fed into the mesophilic digester, it could be detected in the aqueous phase to some extends. The pharmaceuticals present in the biosolid could, on the one hand, be biodegraded, on the other hand, be released into the aqueous phase for the further degradation. At this time, it was hardly to make clear the proportions of the biodegradation in the biosolid/ sludge phase and the aqueous phase as well as the desorption from the biosolid. The removal of PhACs for the digested biosolid could be composed of the three parts. Figures 1 and 2 show the selected PhACs in the biosolid/ sludge phase and aqueous phase during the mesophilic AD at SRT 15 days. Nearly all the selected PhACs in the aqueous were below $0.3 \mu \mathrm{g} / \mathrm{L}$ during the experimental period. In contrast, the selected $\mathrm{PhACs}$ in the biosolid/ sludge phase were at $1.0-3.5 \mu \mathrm{g} / \mathrm{L}$, showing a considerable residue still present in the digested sludge. Also, it implied that adsorption to the biosolid could not be inconsiderable factor during the ADs.

It can be seen from Figs. 1 and 2 that DCF in the aqueous is kept at about $0.05 \mu \mathrm{g} / \mathrm{L}$, and CFA and TCS are kept at about $0.1 \mu \mathrm{g} / \mathrm{L}$. However, a relatively larger variation happened to CBM in the aqueous phase, even above $0.3 \mu \mathrm{g} / \mathrm{L}$ in one sampling. The variation might be due to cleavage of the glucuronide conjugate of CBM during the $\mathrm{AD}$ and subsequent release of the free forms of the 


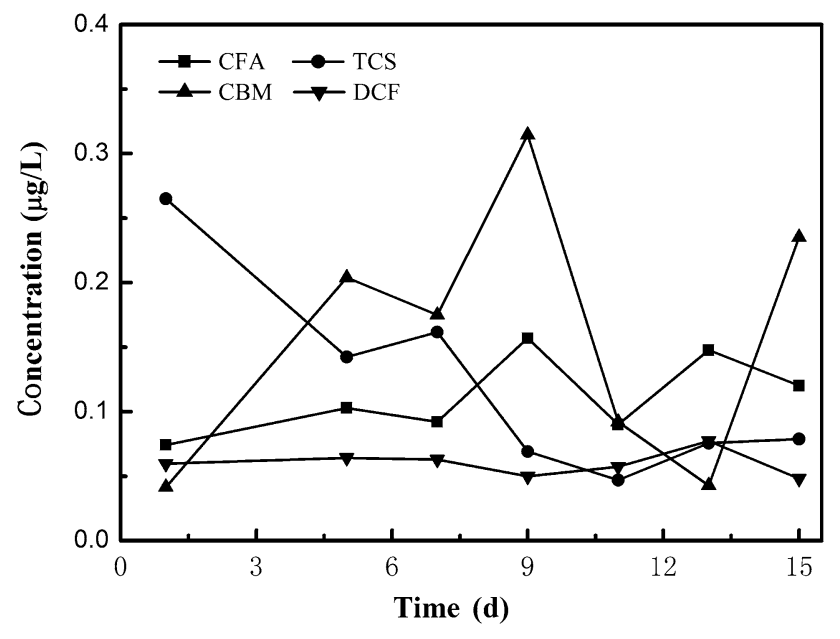

Fig. 1 Selected $\mathrm{PhACs}$ in the aqueous phase during mesophilic anaerobic digestion at SRT 15 days (all the data obtained from the means of the repeated samples)

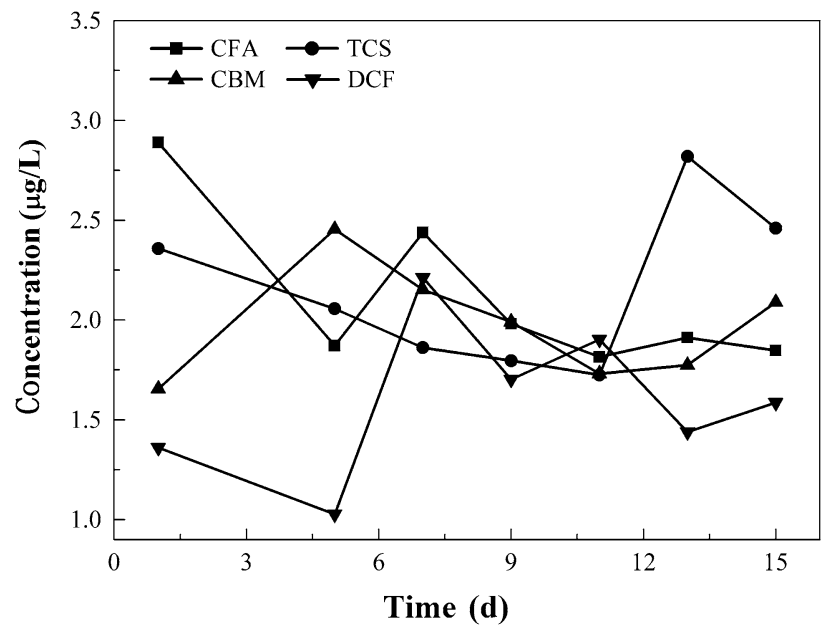

Fig. 2 Selected PhACs in the biosolid phase during mesophilic anaerobic digestion at SRT 15 days (all the data obtained from the means of the repeated samples)

compound in the aqueous phase (Vieno et al. 2006). Compared CFA with TCS in the aqueous phase, TCS might be more difficult to be removed in this phase as the initial concentration of TCS should be lower than that of CFA due to weaker desorption of TCS from the biosolid, according to their $K_{\text {ow }}$ (4.8 for TCS (Ying et al. 2007) and 2.84 for CFA (Ferrari et al. 2003)).

According to the selected PhACs in the two phases aforementioned, the overall removal of the compounds during the $\mathrm{AD}$ could be obtained. Table 4 presents the overall removal of all the compounds during the mesophilic AD at three SRTs. The removal of the selected PhACs went up with the increase of SRTs from 10 to 20 days. In particular, TCS demonstrated a distinct trend of the increase, and its overall removal efficiency was raised from $44 \%$ at SRT 10 days to about $74 \%$ at SRT 20 days. The other three compounds also showed the increases on their overall removal efficiencies to certain extents with the extension of SRTs. It could be seen from Table 4 that SRT has a great influence on the removal of the selected PhACs, and the increase on SRT will positively benefit the removal.

Thermophilic anaerobic digestion The thermophilic AD was also operated at three SRTs. The proportions of the selected PhACs in the biosolid/sludge phase and aqueous phase showed the variation tendencies similar to those in the mesophilic mode. However, there were still some differences between the two modes considering the measured data. The overall removal of the four PhACs during the thermophilic AD at three SRTs is presented in Table 4. In general, the removal of the selected PhACs increased with the SRTs from 7 to 20 days. Notwithstanding, the increases on the removal of CFA and TCS were unconspicuous when the SRT was set above 15 days, and the other two compounds, CBM and DCF, also obtained very slow increases on their removal. Therefore, SRTs also influenced considerably the removal of the selected PhACs, and the extension on SRTs would be helpful for the removal.

Comparisons of PhACs during mesophilic and thermophilic anaerobic digestions Operating temperature is also an important factor affecting the performances of ADs on the removal of the selected PhACs, which could be verified by the above measured data. However, the four targets demonstrated inconsistent influences of the operating temperature during the thermophilic and mesophilic modes. It could be seen from Table 4 that a big increase on the overall removal of TCS at SRT 15 days from $50 \%$ (under mesophilic condition) to the maximal $74 \%$ (under thermophilic condition) is obtained. The increase on the operating temperature would also benefit the removal of CBM, showing slight rises at every set SRTs $(P<0.05$ according to the Dunnett's test). However, the operating temperature did not significantly affect the removal of CFA $(P=0.682)$. Furthermore, the comparison of the overall removal of DCF in the two modes presented the negative impact of the operating temperature $(P<0.05)$. The thermophilic operation would lead to the perceptible decrease on the removal of DCF during AD at the set SRTs. The decrease on the DCF removal might be due to the increase on the inhibition of DCF to the related anaerobic bacteria 
Table 4 The overall removal of the selected PhACs during mesophilic and thermophilic ADs at three SRTs $(n \geq 5)$

\begin{tabular}{|c|c|c|c|c|c|c|c|c|c|}
\hline \multirow[t]{2}{*}{ Anaerobic digestion } & \multirow[t]{2}{*}{ SRT (days) } & \multicolumn{2}{|l|}{ CFA } & \multicolumn{2}{|l|}{ TCS } & \multicolumn{2}{|l|}{ CBM } & \multicolumn{2}{|l|}{ DCF } \\
\hline & & $\begin{array}{l}\text { Digested } \\
\text { sludge } \\
(\mu \mathrm{g} / \mathrm{L})\end{array}$ & $\begin{array}{l}\text { Removal } \\
\text { efficiency } \\
(\%)\end{array}$ & $\begin{array}{l}\text { Digested } \\
\text { sludge } \\
(\mu \mathrm{g} / \mathrm{L})\end{array}$ & $\begin{array}{l}\text { Removal } \\
\text { efficiency } \\
(\%)\end{array}$ & $\begin{array}{l}\text { Digested } \\
\text { sludge } \\
(\mu \mathrm{g} / \mathrm{L})\end{array}$ & $\begin{array}{l}\text { Removal } \\
\text { efficiency } \\
(\%)\end{array}$ & $\begin{array}{l}\text { Digested } \\
\text { sludge } \\
(\mu \mathrm{g} / \mathrm{L})\end{array}$ & $\begin{array}{l}\text { Removal } \\
\text { efficiency } \\
(\%)\end{array}$ \\
\hline \multirow[t]{3}{*}{ Mesophilic } & 10 & $2.1 \pm 0.3$ & $57 \pm 6$ & $2.8 \pm 0.3$ & $44 \pm 6$ & $2.5 \pm 0.4$ & $50 \pm 8$ & $2.1 \pm 0.1$ & $59 \pm 2$ \\
\hline & 15 & $1.9 \pm 0.2$ & $61 \pm 4$ & $2.5 \pm 0.2$ & $50 \pm 4$ & $2.3 \pm 0.2$ & $54 \pm 4$ & $1.6 \pm 0.1$ & $67 \pm 2$ \\
\hline & 20 & $1.8 \pm 0.1$ & $63 \pm 2$ & $1.27 \pm 0.2$ & $74 \pm 4$ & $2.0 \pm 0.3$ & $59 \pm 6$ & $1.4 \pm 0.3$ & $71 \pm 6$ \\
\hline \multirow[t]{3}{*}{ Thermophilic } & 7 & $2.2 \pm 0.3$ & $57 \pm 6$ & $2.4 \pm 0.3$ & $52 \pm 6$ & $2.6 \pm 0.2$ & $48 \pm 4$ & $2.4 \pm 0.2$ & $52 \pm 4$ \\
\hline & 15 & $1.7 \pm 0.1$ & $64 \pm 2$ & $1.3 \pm 0.2$ & $74 \pm 4$ & $2.1 \pm 0.1$ & $56 \pm 2$ & $1.9 \pm 0.3$ & $60 \pm 6$ \\
\hline & 20 & $1.6 \pm 0.2$ & $65 \pm 4$ & $1.3 \pm 0.1$ & $74 \pm 2$ & $1.9 \pm 0.4$ & $61 \pm 8$ & $1.8 \pm 0.2$ & $63 \pm 4$ \\
\hline
\end{tabular}

with the rise of the temperature. Therefore, the mesophilic mode seemed to be more favorable to the removal of DCF.

In general, the maximal overall removal was about $65 \%$ for CFA, obtained in the thermophilic mode at SRT 20 days, and up to $74 \%$ for TCS obtained in the thermophilic mode at SRT 15 days, $61 \%$ for CBM obtained in the thermophilic mode at SRT 20 days, and $71 \%$ for DCF obtained in the mesophilic mode at SRT 20 days. All the compounds could be partially removed during the AD processes, and they might enter into the natural environment when discharged or reused, causing potential environmental risk. Besides, the selected PhACs could be biodegraded into intermediate products (Coelho et al. 2009), which were not detected in this study, and might still cause, even enhance the eco-environmental risks. Therefore, some technical measures are expected to take to enhance the performances of the AD processes on their removal. Also, further study is being conducted in our lab to analyze the intermediate products and their final removal paths of the compounds during the AD of sewage sludge.

The overall removal efficiency of DCF was comparable to the previous study reported by Carballa et al. (2007) in which the mesophilic and thermophilic ADs of selected pharmaceuticals including DCF and CBM at different SRTs were investigated. The removal of DCF was in the range of $69 \pm 10 \%$ in that previous study. Besides, DCF under the mesophilic condition could also obtain the relatively higher removal than under the thermophilic condition. However, CBM showed no elimination, differently from its partial removal obtained in this study. The differences between the two studies might be partly attributed to the initial concentrations of the compound in the feeding sewage sludge. The much higher-level compound was spiked into the sludge before feeding, possibly leading to some inhibitions to its removal. Another reason might be the source of the raw sewage sludge. In this study, the raw sewage sludge was from circulation lines of biological treatment units in the STP. The sludge possessed the property of excellent bioactivity and facultative anaerobic bacteria, which could be cultivated into anaerobic-activated sludge with no great difficulty, maintaining stable content of bacteria for anaerobic digestion. As for the removal of TCS during ADs, there also existed big differences among the previous studies. Samaras et al. (2013) investigated several PhACs in the two full-scale STPs of Greece and found the removal rate of TCS using the mesophilic AD was about $22 \%$. Higher removal rates (30-50 \%) were obtained by Narumiya et al. (2013) who conducted the survey of the fate of pharmaceuticals and personal products (PPCPs) including TCS during the mesophilic and thermophilic ADs in the four full-scale STPs. However, another mesophilic AD experiment using anaerobic soil (Ying et al. 2007) showed TCS could hardly be removed within 70 days of the experimental periods. The slightly higher removal efficiency of TCS was got in this study. To the best of our knowledge, there has been no report on the behavior of CFA using ADs for the time being. Notwithstanding, Salgado et al. (2012) studied the biotransformation of CFA in aerobic sequencing batch reactors (SBRs) with mixed microbial cultures, monitoring the efficiency of biotransformation of CFA and the production of metabolites. The maximum removal achieved was $51 \%$. They concluded that CFA was indeed biodegradable.

Influences of $\mathrm{NH}_{3}-\mathrm{N}$ on PhACs removal during anaerobic digestions $\mathrm{NH}_{3}-\mathrm{N}$ is also considered as an important factor affecting the performances of ADs. The effects of $\mathrm{NH}_{3}-\mathrm{N}$ on the removal of PhACs during ADs in the mesophilic and thermophilic modes were preliminarily investigated and analyzed. Figures 3 and 4 depict the 


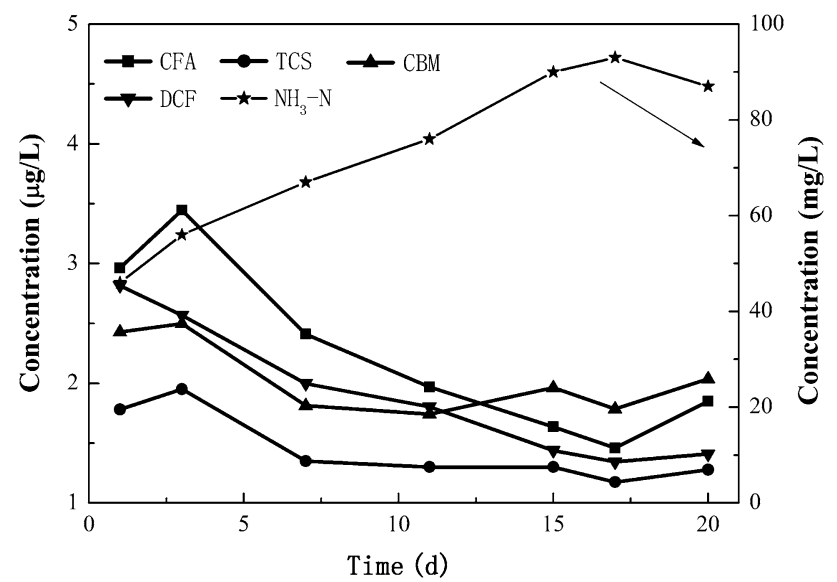

Fig. 3 Variations of the selected $\mathrm{PhACs}$ and $\mathrm{NH}_{3}-\mathrm{N}$ concentrations in the mesophilic anaerobic digestion during one SRT (20 days) of experimental period (all the data obtained from the means of the repeated samples)

overall variations of the selected $\mathrm{PhACs}$ with the $\mathrm{NH}_{3}-\mathrm{N}$ concentrations in the mesophilic and thermophilic modes during one SRT (20 days) of experimental period. For other set SRTs, the similar trends of the variations were observed.

$\mathrm{NH}_{3}-\mathrm{N}$ went up gradually during the initial 15 days and then leveled off with the maximal measured concentration about $95 \mathrm{mg} / \mathrm{L}$ in the mesophilic mode (Fig. 3). CBM and TCS went down during the initial 7 days, and at that time, $\mathrm{NH}_{3}-\mathrm{N}$ was about $63 \mathrm{mg} / \mathrm{L}$. Then, little variations of the two compounds were observed with the increase of $\mathrm{NH}_{3}-\mathrm{N}$. As for DCF, it continued to decrease till the 15th day when $\mathrm{NH}_{3}-\mathrm{N}$ was up to $90 \mathrm{mg} / \mathrm{L}$, and then, it leveled off. In the case of CFA, its drop was observed during the initial 17 days, and at that time, $\mathrm{NH}_{3}-\mathrm{N}$ was about $95 \mathrm{mg} /$ $\mathrm{L}$. Therefore, it seemed that the variations and removal of the selected PhACs might have some bearings with $\mathrm{NH}_{3}-\mathrm{N}$ accumulation in the mesophilic mode, and a gentle accumulation on $\mathrm{NH}_{3}-\mathrm{N}$ might bring a positive effect on the removal of a compound. In the measured range of $\mathrm{NH}_{3}-\mathrm{N}$ concentration in this study, the favorable accumulation levels of $\mathrm{NH}_{3}-\mathrm{N}$ were different among the target compounds.

Similar variations of $\mathrm{NH}_{3}-\mathrm{N}$ were observed in the thermophilic mode (Fig. 4). However, except CFA that showed its continuous decrease till $\mathrm{NH}_{3}-\mathrm{N}$ accumulation to about $97 \mathrm{mg} / \mathrm{L}$ during the initial 13 days, similar to that in the mesophilic mode, the other three compounds presented little variations, and $\mathrm{NH}_{3}-\mathrm{N}$ accumulation in the measured

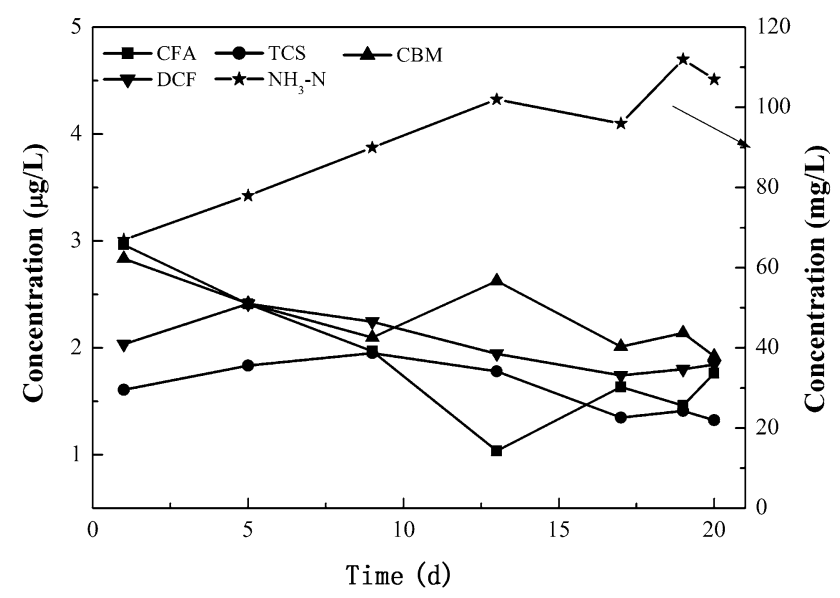

Fig. 4 Variations of the selected $\mathrm{PhACs}$ and $\mathrm{NH}_{3}-\mathrm{N}$ concentrations in the thermophilic anaerobic digestion during one SRT (20 days) of experimental period (all the data obtained from the means of the repeated samples)

range had imperceptible impacts on their removal. Therefore, it seemed that $\mathrm{NH}_{3}-\mathrm{N}$ accumulation would positively affect the removal of the selected PhACs more in the mesophilic mode than in the thermophilic mode.

\section{Conclusion}

PhACs can be detected in the sludge, and their direct environmental harms and potential environmental risks are increasingly concerned. AD processes are mostly used for sewage sludge treatment and stabilization before its final disposal and/or resource reuse. Therefore, it is reasonable to investigate the behavior and removal of PhACs during ADs of sewage sludge. AD processes operated in the mesophilic and thermophilic modes could partly remove PhACs from the sludge; however, their overall removal was limited, and their residues and intermediate products in the sludge would still bring potential environmental risks. Therefore, further measures are expected to take to enhance the performances of ADs on their removal.

Sludge retention time and operating temperature are two important factors affecting the performances of ADs. The increases on SRTs could lead to the rises on the removal of the selected PhACs. The thermophilic mode would be more helpful for the removal of CBM and TCS, however, not have a noticeable effect on the removal of CFA. Furthermore, the removal of DCF was found more effective in the mesophilic mode. Besides, CFA, firstly reported in this 
study, could obtain maximal $65 \%$ removal efficiency during ADs of sewage sludge. In addition, $\mathrm{NH}_{3}-\mathrm{N}$ accumulation to its favorable levels might affect positively the removal of the selected PhACs, especially in the mesophilic mode.

Acknowledgments This work was financially supported by the National Natural Science Foundation of China (NSFC) (Grant No. 51279108), the Innovation Program of Shanghai Municipal Education Commission, China (12YZ100), the Major Project of Shanghai Municipal Science and Technology Commission (13DJ1400105), and the special fund of State Key Joint Laboratory of Environment Simulation and Pollution Control (12K11ESPCT).

\section{References}

Aguayo S, Torre ADL, Carballo M, Cabrera R, Méndez J (2010) A review of the most relevant residues of pharmaceuticals products of human use in effluents and sludges from waste water treatment plants. Toxicol Lett 196(Supplement 1):S65

Barnab S, Brar SK, Tyagi RD, Beauchesne I, Surampalli RY (2009) Pre-treatment and bioconversion of wastewater sludge to valueadded products-fate of endocrine disrupting compounds. Sci Total Environ 407(5):1471-1488

Carballa M, Omil F, Ternes T, Lema JM (2007) Fate of pharmaceutical and personal care products (PPCPs) during anaerobic digestion of sewage sludge. Water Res 41(10):2139-2150

Clesceri L, Greenberg A, Eaton A (2001) Standard methods for the examination of water and wastewater, 20th edn. American Public Health Association, Washington

Coelho AD, Sans C, Agüera A, Gómez MJ, Esplugas S, Dezotti M (2009) Effects of ozone pre-treatment on diclofenac: intermediates, biodegradability and toxicity assessment. Sci Total Environ 407:3572-3578

Coelho NM, Droste RL, Kennedy KJ (2011) Evaluation of continuous mesophilic, thermophilic and temperature phased anaerobic digestion of microwaved activated sludge. Water Res 45(9):2822-2834

Ferrari B, Paxeus N, Giudice RL, Pollio A, Garric J (2003) Ecotoxicological impact of pharmaceuticals found in treated wastewaters: study of carbamazepine, clofibric acid, and diclofenac. Ecotoxicol Environ Saf 55(3):359-370

Garfí M, Gelman P, Comas J, Carrasco W, Ferrer I (2011) Agricultural reuse of the digestate from low-cost tubular digesters in rural Andean communities. Waste Manag 31(12):2584-2589

Heberer T (2002) Occurrence, fate, and removal of pharmaceutical residues in the aquatic environment: a review of recent research data. Toxicol Lett 131(1-2):5-17

Hospido A, Carballa M, Moreira M, Omil F, Lema JM, Feijoo G (2010) Environmental assessment of anaerobically digested sludge reuse in agriculture: potential impacts of emerging micropollutants. Water Res 44(10):3225-3233

Jang HM, Cho HU, Park SK, Ha JH, Park JM (2014) Influence of thermophilic aerobic digestion as a sludge pre-treatment and solids retention time of mesophilic anaerobic digestion on the methane production, sludge digestion and microbial communities in a sequential digestion process. Water Res 48:1-14

Jelic A, Gros M, Ginebreda A, Cespedes-Sánchez R, Ventura F, Petrovic M, Barcelo D (2011) Occurrence, partition and removal of pharmaceuticals in sewage water and sludge during wastewater treatment. Water Res 45(3):1165-1176

Khan SJ, Ongerth JE (2002) Estimation of pharmaceutical residues in primary and secondary sewage sludge based on quantities of use and fugacity modelling. Water Sci Technol 46(3):105-113

Lee J, Ji K, Kho YL, Kim P, Choi K (2011) Chronic exposure to diclofenac on two freshwater cladocerans and Japanese medaka. Ecotoxicol Environ Saf 74(5):1216-1225

Li YL, Liu JW, Chen JY, Shi YF, Mao W, Liu H, Li Y, He S, Yang JK (2014) Reuse of dewatered sewage sludge conditioned with skeleton builders as landfill cover material. Int J Environ Sci Technol 11(1):233-240

Merrylin J, Kaliappan S, Kumar SA, Yeom IT, Rajesh BJ (2013) Effect of extracellular polymeric substances on sludge reduction potential of Bacillus licheniformis. Int J Environ Sci Technol 10(1):85-92

MOCC (2005) Determination method for municipal sludge in wastewater treatment plant (CJ/T 221-2005). China Standard Press, Beijing

Mudhoo A, Kumar S (2013) Effects of heavy metals as stress factors on anaerobic digestion processes and biogas production from biomass. Int J Environ Sci Technol 10(6):1383-1398

Narumiya M, Nakada N, Yamashita N, Tanaka H (2013) Phase distribution and removal of pharmaceuticals and personal care products during anaerobic sludge digestion. J Hazard Mater. doi:10.1016/j.jhazmat.2013.05.032

Nassef M, Matsumoto S, Seki M, Khalil F, Kang IJ, Shimasaki Y, Oshima Y, Honjo T (2010) Acute effects of triclosan, diclofenac and carbamazepine on feeding performance of Japanese medaka fish (Oryzias latipes). Chemosphere 80(9):1095-1100

Radjenovic J, Petrovic M, Barcelo D (2009) Fate and distribution of pharmaceuticals in wastewater and sewage sludge of the conventional activated sludge (CAS) and advanced membrane bioreactor (MBR) treatment. Water Res 43(3):831-841

Salgado R, Oehmen A, Carvalho G, Noronha JP, Reis MA (2012) Biodegradation of clofibric acid and identification of its metabolites. J Hazard Mater 241-242:182-189

Samaras VG, Stasinakis AS, Mamais D, Thomaidis NS, Lekkas TD (2013) Fate of selected pharmaceuticals and synthetic endocrine disrupting compounds during wastewater treatment and sludge anaerobic digestion. J Hazard Mater 244-245:259-267

Saravanan M, Karthika S, Malarvizhi A, Ramesh M (2011) Ecotoxicological impacts of clofibric acid and diclofenac in common carp (Cyprinus carpio) fingerlings: hematological, biochemical, ionoregulatory and enzymological responses. J Hazard Mater 195:188-194

Triebskorn R, Casper H, Heyd A, Eikemper R, Köhler HR, Schwaiger $\mathrm{J}$ (2004) Toxic effects of the non-steroidal anti-inflammatory drug diclofenac. Aquat Toxicol 68(2):151-166

Vieno NM, Tuhkanen T, Kronberg L (2006) Analysis of neutral and basic pharmaceuticals in sewage treatment plants and in recipient rivers using solid phase extraction and liquid chromatography-tandem mass spectrometry detection. J Chromatogr A 1134(1-2):101-111

Yang X, Flowers RC, Weinberg HS, Singer PC (2011) Occurrence and removal of pharmaceuticals and personal care products (PPCPs) in an advanced wastewater reclamation plant. Water Res 45(16):5218-5228

Ying G, Yu X, Kookan RS (2007) Biological degradation of triclocarban and triclosan in a soil under aerobic and anaerobic conditions and comparison with environmental fate modelling. Environ Pollut 15:300-305 
Zhou H, Wu C, Huang X, Gao M, Wen X, Tsuno H, Tanaka H (2010) Occurrence of selected pharmaceuticals and caffeine in sewage treatment plants and receiving rivers in Beijing, China. Water Environ Res 82(11):2239-2248
Zhou H, Zhou Y, Li H, Wang F (2012) Fate and removal of selected endocrine-disrupting compounds in sewage using activated sludge treatment. Water Environ J 26:435-444 